\title{
EDITORIAL NOTE ON REPRODUCTIVE BIOLOGY OF FISHES
}

\author{
Athanassios C. TSIKLIRAS ${ }^{1 *}$, Konstantinos I. STERGIOU ${ }^{1}$, and Rainer FROESE ${ }^{2}$ \\ ${ }^{1}$ Laboratory of Ichthyology, Department of Zoology, School of Biology, Aristotle University of Thessaloniki, \\ Thessaloniki, Greece \\ ${ }^{2}$ Helmholtz Institute for Ocean Research, GEOMAR, Kiel, Germany
}

Tsikliras A.C., Stergiou K.I., Froese R. 2013. Editorial note on reproductive biology of fishes. Acta Ichthyol. Piscat. 43 (1): 1-5.

\begin{abstract}
Fish reproductive biology (onset and duration of spawning, sex ratio, maturity stages, length and age at maturity, and fecundity) is important in fisheries research, stock assessment, and management. In this editorial note, we provide some criteria and recommendations on issues of fish reproductive biology, which may be useful in research planning, data analysis and presentation, as well as in manuscript preparation.
\end{abstract}

The population characteristics of fishes, and in particular those concerning their reproduction, are very important inputs in the assessment and management of fish stocks (e.g., Froese 2004). For reliable stock assessments, one needs to ensure that the underlying parameters had been estimated accurately and precisely on unbiased sample collections and robust estimation techniques (Jennings et al. 1998). Various management measures rely completely upon the reproductive characteristics of stocks (Morgan 2008), including minimum landing size (MLS), closed fishing seasons, closed areas, and the compulsory release of egg-bearing females of some species of decapod crustaceans (e.g., European Regulation 1967/2006; Moroccan Royal Decree 1-73-255 of 1973).

The number of articles published in the primary literature that deal with the reproductive biology of fishes has increased progressively with time (for the Mediterranean Sea; see Tsikliras et al. 2010, Tsikliras and Stergiou unpublished $^{* *}$ ). Globally, since 2002, such articles have averaged $>1100$ items per year (Fig. 1). However, this information comes in a wide variety of formats and thus is difficult to compile and analyze.

In this editorial note, as we did with the one on weight-length relations of fishes (Froese et al. 2011), we provide recommendations on various aspects of the reproductive biology of fishes (e.g., sampling, reporting, and statistics) that may be useful in research planning, data analysis, presentation, and manuscript preparation.

\section{Definitions and general suggestions}

Ideally, the onset and duration of spawning, maturation stages (identified macroscopically, microscopically, or histologically), length- $\left(L_{\mathrm{m}}\right)$ and age $\left(t_{\mathrm{m}}\right)$ at first matu- rity, sex ratio, and fecundity should all be included in a single manuscript, since all these aspects constitute the reproductive biology of a species. The compilation of such information, based on new data but including a review of relevant studies, will justify a stand-alone publication for a single species. Exceptional behavioural patterns or tactics (e.g., bourgeois and parasitic sperm competing males: Taborsky 1998, Gonçalves et al. 2005) and diversions from the norm (e.g., unexpected reproductive strategy: Freon et al. 1997) may need more research and discussion and justify also a research article. Ichthyoplankton surveys also provide important information on the spawning of fishes, such as defining the extent of the spawning period (e.g., Tsikliras et al. 2010), but are not considered here as they belong to a scientific field of their own.

The publications we are considering here would be typically entitled "The reproductive biology of [common name], [scientific name]". In the introduction, semelparity (most fish die after reproduction) and iteroparity (fish with multiple spawning events) should be clearly identified. The gender system (i.e., gonochoristic: male and female reproductive organs are in different individuals; hermaphroditic: an individual possesses both male and female reproductive organs; gynogenetic and hybridogenetic: unisexual reproduction) and any particular reproductive traits or tactics, such as spawning site preparation (nesters) and guarding (guarders) or other form of parental care, should be described briefly. There are still some well-studied, commercial fishes for which the gender system is questioned or has not yet been confirmed (Sadovy de Mitcheson and Liu 2008). Thus, the type of

\footnotetext{
* Correspondence: Athanassios C. Tsikliras: atsik@bio.auth.gr; Konstantinos I. Stergiou: kstergio@bio.auth.gr; Rainer Froese: rfroese@geomar.de.

${ }^{* *}$ Tsikliras A.C., Stergiou K.I. Size at maturity of Mediterranean marine fishes. (submitted to: Reviews in Fish Biology and Fisheries).
} 
hermaphroditism should be included in detail, i.e., whether the species studied is a simultaneous hermaphrodite (active male and active female reproductive organs are present at the same time) or a sequential hermaphrodite (protandrous: individuals develop into males first and then transform to females; protogynous: individuals develop into females first and then transform to males).

Although parental care after egg laying is generally not studied as part of the fish reproductive biology, this behaviour is very important because it is often traded off with reproductive characteristics, such as oocyte number (Gross 2005). Non-behavioural forms of parental care characterized by the retention of fertilized eggs within the female reproductive tract (Clutton-Brock 1991), such as ovoviparity (eggs retained in the body and embryos are nourished from yolk) and viviparity (eggs develop in the oviduct or uterus and embryos are nourished directly from the mother) of elasmobranchs (and some actinopterygians), should also be mentioned.

Ovarian development organization (synchronous: all oocytes develop and ovulate at the same time; group synchronous: at least two populations of oocytes can be recognized at any time; asynchronous: oocytes of all stages are present without dominant populations), type of fecundity (determinate fecundity: recruitment of oocytes from primary to secondary growth occurs prior to an individual's spawning period; indeterminate fecundity: recruitment of oocytes from primary to secondary growth stage continues throughout an individual's spawning period) and type of spawning (batch spawning: females, with either determinate or indeterminate fecundity, are capable of ovulating and spawning multiple batches of oocytes during the individual spawning period; total spawning: females ovulate and spawn all developing oocytes in a single event; fractional spawning: females ovulate and spawn all developing oocytes over a very short time period as part of a single episode) are prerequisites when fecundity is studied and the appropriate terminology should be used consistently (West 1990, Murua and Saborido-Rey 2003, Murua et al. 2003, Brown-Peterson et al. 2011, Lowerre-Barbieri et al. 2011a).

Please find below our recommendations regarding sampling, reporting, and statistics:

\section{General}

1. The sampling frequency and duration and the fishing/sampling gear or collection method (i.e., gear type, mesh/hook size), used for the collection of samples should be described.

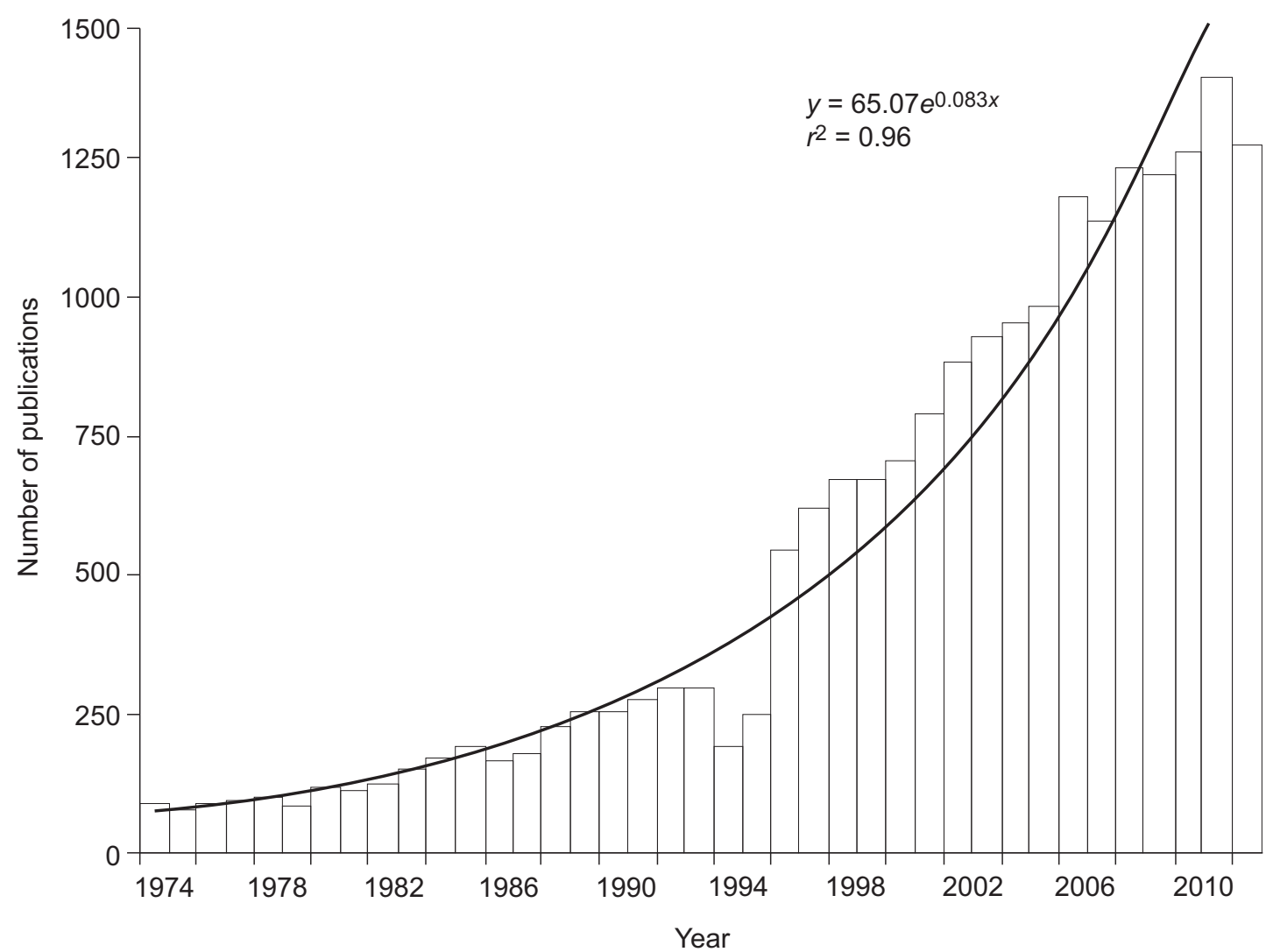

Fig. 1. The number of scientific articles on fish reproductive biology published during 1974-2012, based on data from Scopus (Anonymous 2012); The columns represent articles that included the words "spawning" or "maturity" or "fecundity" or "reproduction" or "reproductive biology" and "fish" in the field "Article Title, Abstract and Keywords" ( $n=20300$ for 1974-2012); The majority of the relevant articles were published in: Journal of Fish Biology, Aquaculture, Environmental Biology of Fishes, General and Comparative Endocrinology, Canadian Journal of Fisheries and Aquatic Sciences, Fisheries Research, Transactions of the American Fisheries Society, ICES Journal of Marine Science, Marine Ecology Progress Series, and Hydrobiologia 
2. The minimum and maximum recorded total lengths (TL) should be provided for both sexes, but also for unsexed individuals (if any).

3. The number of specimens collected per sampling event per gender should be given.

Such recommendations might seem trivial but, in $\sim 7 \%-18 \%$ of the papers reviewed in two reviews on the spawning and maturity of Mediterranean marine fishes (Tsikliras et al. 2010, Tsikliras and Stergiou unpublished*), information on (1), (2), and (3) was not provided.

\section{Onset and duration of spawning}

4. When aiming to determine the onset and duration of spawning the sampling frequency should be at least monthly. However, a more frequent sampling might be necessary in some cases (e.g., batch spawning). The sampling period should extend over at least two full year cycles in order to identify any interannual variation in the onset and duration of spawning (e.g., Tsikliras and Antonopoulou 2006).

5. The gonadosomatic index (GSI), which is the ratio of gonad mass to total body mass, remains the best predictor of spawning period, (i.e., onset and duration of spawning). Time series of GSI values per sampling event (time) should be plotted by gender, preferably as a box-and-whisker plot or as means with standard errors, in order for the range of individual values to be apparent. GSI can be also plotted against other variables, such as lipid content, hepatosomatic index, and condition factor.

6. The range of GSI values should be clearly stated by gender because female GSI is used for the estimation of natural mortality $(M)$ in the empirical equation $(M=0.03+1.68 \times \mathrm{GSI})$ of Gunderson and Dygert (1988)

7. The monthly proportion (percentage) of maturity stages per gender (plotted as $100 \%$ stacked columns) can also be used as an indicator of the spawning period.

\section{Sex ratio}

8. Monthly sex ratios (usually presented as females to males, F : M) are necessary if a specific hypothesis is tested (e.g., females disappearing from catches during their spawning period: Blaxter and Hunter 1982). If included, they should be given preferably in a figure or as online supplementary material (rather than in a Table).

9. Size-specific sex ratios are also important indicators of growth and mortality and could also be provided. In case of space limitation, such information can be provided as online supplementary material.

10. In sequential hermaphrodites, it is important that gender inversion length is shown graphically.

11. Overall sex ratio could be compared with the theoretical $1: 1$ ratio, which is expected to occur in nature (Charnov 1993). The comparison of the observed sex ratio with the theoretical one is performed using chisquared test $\left(\chi^{2}\right)$, available in all statistical packages.

\section{Length at maturity}

12. Coverage of a wide length range (from juveniles to adults approximating their asymptotic length), preferably with the number of specimens being equally dis- tributed among length classes, is important for an unbiased estimation of $L_{\mathrm{m}}$ and $t_{\mathrm{m}}$, in order to avoid their over- or underestimation. Thus, samples taken with selective gear types (e.g., a single mesh size of gillnets or a single hook size in longlines) are not generally appropriate because of the narrow length ranges sampled.

13. Although the classification of gonads to maturity stages based on histology is considered more accurate, the preparation of histological slides is not always feasible (e.g., onboard the commercial fleets) and is rather costly (in terms of labour, equipment, and consumables). Therefore, the macroscopic classification of gonads to maturity stages is acceptable.

14. The majority of reproductive biology studies use the general maturity scale of Nikolsky (1963) with slight modifications. However, species-specific maturity scales are also available for an increasing number of species. Recently, a universal maturity scale has been proposed for oviparous fishes (Núñez and Duponchelle 2009). If the universal scale cannot be used, we suggest the use of the classic Nikolsky scale only when a species-specific one is not available.

15. The criteria used for the level of gonadal development that represents immature/mature individuals should be clearly stated (Lowerre-Barbieri et al. 2011b).

16. The $L_{\mathrm{m}}$ should be always defined. Various definitions have been used:

(a) The length at which $50 \%$ of the population become mature for the first time;

(b) The length at which a certain percentage (other than $50 \%$ ) of the population becomes mature;

(c) The length of the smallest mature fish;

(d) The length of the largest fish maturing for the first time;

(e) As a range of the length or age of smallest to the largest mature fish (points $\mathrm{c}$ and $\mathrm{d}$ ); and

(f) As a range of the mean length at maturity (Binohlan 1998). We believe that the first definition is the most appropriate one and should be used for defining $L_{\mathrm{m}}$.

17. The method for estimating $L_{\mathrm{m}}$ should be clearly stated. We suggest the use of maturity ogives (i.e., plots of proportion mature individuals against length class) upon which the logistic regression-the most commonly used method (Lowerre-Barbieri et al. 2011b) - is fitted. Deviance statistics should be provided to facilitate checking the fit of the logistic model to the data (see Petrakis and Stergiou 1997).

18. From the logistic regression of proportion mature with length and age, the equation and parameters should be shown on the corresponding figure. $L_{25}$ (the length at which $25 \%$ of the population are sexually mature) and $L_{75}$ (the length at which $75 \%$ of the population are sexually mature) may be useful but not essential (Stergiou 1999). To avoid capture of juveniles, the length at which $90 \%$ of the more numerous gender are mature is of special interest to management.

19. If there remains doubt about $L_{\mathrm{m}}$ because of too few data, empirical equations that have been proposed for

\footnotetext{
${ }^{*}$ See footnote on page 1 .
} 
Actinopterygii and Elasmobranchii (see Binohlan and Froese 2009, Tsikliras and Stergiou unpublished*) could be used to assess the likelihood of the doubtful estimate.

20. The dimensionless ratios $L_{\mathrm{m}}: L_{\max }$, which approximates reproductive load (Longhurst and Pauly 1987), and $h$ : $h=\left(L_{\mathrm{m}} \cdot L_{\infty}{ }^{-1}-1\right) \cdot\left(L_{\mathrm{m}} \cdot L_{\infty}{ }^{-1}\right)^{-1} \cdot \ln \left(1-L_{\mathrm{m}} \cdot L_{\infty}{ }^{-1}\right)$ which shows the trade off between growth and reproduction (Jennings and Dulvy 2008), could be estimated.

21. A comparison of $L_{\mathrm{m}}$ with MLS (if available) could be presented, whereas, in the absence of MLS for the studied species, a recommendation for the stock is essential.

\section{Fecundity}

22. The preservation technique and the length of time the samples were preserved should be clearly stated because they affect the size and weight of gonads (e.g., Gunderson et al. 2003). Ideally, the preservation technique must be kept the same for all samples.

23. Minimum-, maximum fecundity (and the corresponding TL) and average fecundity (the total number of oocytes in ovaries) should be reported.

24. Relative fecundity (the fecundity divided by the total fish weight) also contains information useful for comparing the reproductive strategies in fish (Pitcher and Hart 1982) and could be provided in terms of body (and ovary) weight.

25. The relation of fecundity with length, weight, age or ovary weight of the fish is essential and should be provided. There is no need for logarithmic transformation unless for comparability purposes with previously published relations. If there is a cloud of data points in the mid-length classes, the average fecundity per length class can be used in order to assign equal weight to all size classes (Živkov and Petrova 1993).

26. If the studied species is a batch spawner, then the fecundity of each batch and frequency among batches should be provided (Hunter and Macewicz 1985, Hunter et al. 1985).

27. From the relation of fecundity with length (weight, age, and ovary weight), the slope $(b)$, the intercept $(a)$, their $95 \%$ confidence limits, the coefficient of determination $\left(r^{2}\right)$, and the sample size $(n)$, should be reported always.

Special recommendations referring to Elasmobranchii

28. For Elasmobranchii the onset of sexual maturity is determined in males by the condition and the length of claspers (pterygiopods) and in females from the condition of ovaries and the morphology of the reproductive tract (e.g., Capapé and Reynaud 2011). The relation between the pterygiopod length and total length may also be used to assess the $L_{\mathrm{m}}$ of males (e.g., Orlov and Smirnov 2011). Both ovarian (the number of developing or yolky oocytes) and uterine (number of encapsulated eggs or developing embryos or near-term embryos) fecundity should be given along with the gestation period.

We hope our guidelines will prove useful in the effort to better understand the reproductive biology of fishes.

\section{ACKNOWLEDGEMENTS}

The authors would like to thank the Editor-in-Chief Wojciech Piasecki and the Editors and Board members of Acta Ichthyologica et Piscatoria: Sanja Matić-Skoko, Alexei M. Orlov, Teresa Ostaszewska, Arun Kumar Ray, Roger Uglow, Ekaterina D. Vasil'eva, Paraskevi Karachle, Brian Coad, Włodzimierz Załachowski, for their helpful comments and suggestions that improved this editorial note.

\section{REFERENCES}

Anonymous 2012. Scopus. [Accessed on 17 November 2012.] http://www.scopus.com

Binohlan C. 1998. The MATURITY table. Pp. 176-179. In: Froese R., Pauly D. (eds.) FishBase 98: Concepts, design and data sources. ICLARM, Manila, Philippines.

Binohlan C., Froese R. 2009. Empirical equations for estimating maximum length from length at first maturity. Journal of Applied Ichthyology 25 (5): 611-613. DOI: 10.1111/j.14390426.2009.01317.x

Blaxter J.H.S., Hunter J.R. 1982. The biology of clupeoid fishes. Advances in Marine Biology 20: 1-223. DOI: 10.1016/S0065-2881(08)60140-6

Brown-Peterson N.J., Wyanski D.M., Saborido-Rey F., Macewicz B.J., Lowerre-Barbieri S.K. 2011. A standardized terminology for describing reproductive development in fishes. Marine and Coastal Fisheries: Dynamics, Management, and Ecosystem Science 3 (1): 52-70. DOI: 10.1080/19425120.2011.555724

Capapé C., Reynaud C. 2011. Maturity, reproductive cycle and fecundity of the spiny dogfish Squalus acanthias (Chondrichthyes: Squalidae) off the Languedocian coast (southern France, northern Mediterranean). Journal of the Marine Biological Biological Association of the United Kingdom 91 (8): 1627-1635. DOI: 10.1017/ S0025315411000270

Charnov E.L. 1993. Life history invariants. Oxford University Press, Oxford, UK.

Clutton-Brock T.H. 1991. The evolution of parental care. Princeton University Press, Princeton NJ, USA.

Fréon P., El Khattabi M., Mendoza J., Guzmán R. 1997. Unexpected reproductive strategy of Sardinella aurita off the coast of Venezuela. Marine Biology 128 (3): 363-372. DOI: $10.1007 / \mathrm{s} 002270050102$

Froese R. 2004. Keep it simple: three indicators to deal with overfishing. Fish and Fisheries 5 (1): 86-91. DOI: 10.1111/j.1467-2979.2004.00144.x

Froese R., Tsikliras A.C., Stergiou K.I. 2011. Editorial note on weight-length relations of fishes. Acta Ichthyologica et Piscatoria 41 (4): 261-263. DOI: 10.3750/AIP2011.41.4.01

Gonçalves D., Matos R., Fagundes T., Oliveira R. 2005. Bourgeois males of the peacock blenny, Salaria pavo, discriminate female mimics from females? Ethology 111 (6): 559-572. DOI: $10.1111 /$ j.1439-0310.2005.01069.x

Gross M.R. 2005. The evolution of parental care. The Quarterly Review of Biology 80 (1): 37-45. DOI: 10.1086/431023

Gunderson D.R., Dygert P.H. 1988. Reproductive effort as a predictor of natural mortality rate. ICES Journal of Marine Science 44 (2): 200-209. DOI: 10.1093/icesjms/44.2.200

\footnotetext{
* See footnote on page 1.
} 
Gunderson D.R., Zimmermann M., Nichol D.G., Pearson K. 2003. Indirect estimates of natural mortality rate for arrowtooth flounder (Atheresthes stomias) and dark-blotched rockfish (Sebastes crameri). Fishery Bulletin 101 (1): 175-182.

Hunter J.R., Lo N.C.H., Leong R.J.H. 1985. Batch fecundity in multiple spawning fishes. NOAA Technical Report NMFS 36: 67-77.

Hunter J.R., Macewicz B.J. 1985. Measurement of spawning frequency in multiple spawning fishes. NOAA Technical Report NMFS 36: 79-94.

Jennings S., Dulvy N.K. 2008. Beverton and Holt's insights into life history theory: influence, application and future use. Pp. 434-450. In: Payne A.I., Cotter A.J.R., Potter E.C.E. (eds.) Advances in fisheries Science: 50 years on from Beverton and Holt. Blackwell Publishing, Oxford, UK. DOI: $10.1002 / 9781444302653 . c h 18$

Jennings S., Reynolds J.D., Mills S.C. 1998. Life history correlates of responses to fisheries exploitation. Proceedings of the Royal Society of London, series B: Biological Sciences 265 (1393): 333-339. DOI: 10.1098/rspb.1998.0300

Longhurst A.R., Pauly D. 1987. Ecology of tropical oceans. Academic Press, San Diego, USA.

Lowerre-Barbieri S.K., Brown-Peterson N.J., Murua H., Tomkiewicz J., D. Wyanski, F. Saborido-Rey. 2011a. Emerging issues and methodological advances in fisheries reproductive biology. Marine and Coastal Fisheries: Dynamics, Management, and Ecosystem Science 3 (1): 32-51. DOI: 10.1080/19425120.2011.555725

Lowerre-Barbieri S.K., Ganias K., Saborido-Rey F., Murua H., Hunter J.R. 2011b. Reproductive timing in marine fishes: variability, temporal scales, and methods. Marine and Coastal Fisheries: Dynamics, Management, and Ecosystem Science 3 (1): 71-91. DOI: 10.1080/19425120.2011.556932

Morgan M.J. 2008. Integrating reproductive biology into scientific advice for fisheries management. Journal of the Northwest Atlantic Fisheries Science 41: 37-51. DOI: 10.2960/J.v41.m615

Murua H., Saborido-Rey F. 2003. Female reproductive strategies of marine fish species of the north Atlantic. Journal of Northwest Atlantic Fisheries Science 33: 23-31.

Murua H., Kraus G., Saborido-Rey F., Thorsen A., Witthames P., Junquera S. 2003. Procedures to estimate fecundity of marine fish species in relation to their reproductive strategy. Journal of the Northwest Atlantic Fisheries Science 33: 33-54.

Nikolsky G.V. 1963. The ecology of fishes. Academic Press, London, UK.
Núñez J., Duponchelle F. 2009. Towards a universal scale to assess sexual maturation and related life history traits in oviparous teleost fishes. Fish Physiology and Biochemistry 35 (1): 167-180. DOI: 10.1007/s10695-008-9241-2

Orlov A.M., Smirnov A.A. 2011. New data on sexual dimorphism and reproductive biology of Alaska Skate Bathyraja parmifera from the Northwestern Pacific Ocean. Journal of Ichthyology 51 (8): 590-603. DOI: 10.1134/ S0032945211050109

Petrakis G., Stergiou K.I. 1997. Size selectivity of diamond and square mesh codends for four commercial Mediterranean fish species. ICES Journal of Marine Science 54 (1): 13-23. DOI: 10.1006/jmsc. 1996.0172

Pitcher T.J., Hart P.J.B. 1982. Fisheries ecology. Chapman and Hall, London, UK.

Sadovy de Mitcheson Y., Liu M. 2008. Functional hermaphroditism in teleosts. Fish and Fisheries 9 (1): 1-43. DOI: 10.1111/j.1467-2979.2007.00266.x

Stergiou K.I. 1999. Intraspecific variations in size- and age-atmaturity for red bandfish, Cepola macrophthalma. Environmental Biology of Fishes 54 (2): 151-160. DOI: 10.1023/A:1007594719450

Taborsky M. 1998. Sperm competition in fish: 'bourgeois' males and parasitic spawning. Trends in Ecology and Evolution 13 (6): 222-227. DOI: 10.1016/S01695347(97)01318-9

Tsikliras A.C., Antonopoulou E. 2006. Reproductive biology of round sardinella (Sardinella aurita) in the north-eastern Mediterranean. Scientia Marina 70 (2): 281-290.

Tsikliras A.C., Antonopoulou E., Stergiou K.I. 2010. Spawning period of Mediterranean marine fishes. Reviews in Fish Biology and Fisheries 20 (4): 499-538. DOI: 10.1007/s11160-010-9158-6

West G. 1990. Methods of assessing ovarian development in fishes: a review. Australian Journal of Marine and Freshwater Research 41 (2): 199-222. DOI: 10.1071/MF9900199

Živkov M., Petrova G. 1993. On the pattern of correlation between fecundity, length, weight and age of pikeperch Stizostedion lucioperca. Journal of Fish Biology 43 (2): 173-182. DOI: 10.1111/j.1095-8649.1993.tb00421.x

Received: 23 February 2013 Accepted: 6 March 2013 Published electronically: 31 March 2013 